\section{Internet como Esfera Pública Global e o Papel Atual dos Parlamentos no Processo Legislativo}

\author{
Internet as a Global Public Sphere and the Role of \\ Parliaments during the Legislative Procedure
}

\section{RESUMO}

A popularização das Tecnologias da Informação e Comunicação trouxe diversas transformações nas várias searas do meio social. Do mercado às instituições públicas, as significativas alterações comportamentais recentes dividem opiniões e esperanças na superação das limitações até então impostos às interações sociais sem tais tecnologias. No campo da representação política e da expressão dos valores democráticos não é diferente. Muitas visões se cindem sobre o presente e o futuro no tocante à manifestação da vontade e exercício da soberania popular. Este trabalho, primeiramente, parte de breve análise sobre o conceito de esfera pública para averiguar as possibilidades de a Internet ser considerada um verdadeiro veículo para a consecução de uma esfera pública em âmbito global. Posteriormente, defronta-se com o problema da atual estrutura da Rede, com funcionamento cada vez mais baseado em interesses privados, o que impõe desafios teóricos e práticos à consecução de um ambiente efetivamente democrático. Finalmente, utiliza-se deste breve arcabouço teórico para discutir o problema de fundo acerca do papel dos parlamentos no funcionamento da democracia contemporânea no processo legislativo.

Palavras-chave: Internet. Direito. Democracia. Esfera Pública. Parlamento.

\section{ABSTRACT}

The popularization of the Information and Communication Technologies brought deep changes in many areas of society. From the market to the public institutions, these significant and recent behavioral modifications has been dividing opinions and hopes in the overcoming of the current limitations imposed to social interactions without these technologies. Talking about the political representation and the expression of the democratic values is not different. It splits opinions about the present and the future in regards of political will and the exercise of popular sovereignty. This work

\section{RUBENS BEÇAK}

Universidade de São Paulo. Faculdade de Direito de Ribeirão Preto, São Paulo, Brasil

Jõ̃o Victor Rozatti L ONG H I

Universidade Federal de Uberlândia. Faculdade de Direito, Minas Gerais, Brasil 
starts first on a brief analysis on the concept of public sphere to inquire the possibilities of the Internet to be considered a true vehicle for the achievement of a global public sphere. Later, it is confronted with the problem of the current structure of the Net, more and more based in private interests, what imposes theoretical and practical challenges to the achievement of a true democratic environment. Finally, all this concepts are used to face the problem about the current role of parliaments in the legislative process in the functioning of the contemporary democracy.

Keywords: Internet. Law. Democracy. Public Sphere. Parliament.

\section{INTRODUÇÃO}

\section{As transformações trazidas pela popularização das tecnologias da informação} e comunicação (TICs), especialmente a Internet, alteraram sensivelmente o cenário político contemporâneo. E este amplo universo de possibilidades para a concretização de valores democráticos como liberdade de expressão e de associação, dentre outros, tem levado muitos a afirmar que o atual ambiente social traz consigo grande potencial para o incremento das instituições democráticas.

Não há dúvida de que a Internet pode melhorar a transparência, a responsabilidade política, entre outras questões que são basilares em um sistema efetivamente democrático. Entretanto, muitos questionam tais assertivas, tendência crescente em parte da literatura especializada nos últimos anos, chegando alguns a afirmar que a dita "democracia digital" seria um verdadeiro mito [21]. E em tempos de "big data"*e as revelações de violação maciça do direito humano à privacidade em escala global, parece que a ideia de uma Internet livre está cada vez mais se tornando uma imagem no passado, o que reforça a profundidade do problema científico a ser enfrentado.

Este trabalho tem por escopo principal abordar alguns dos desafios para que a Internet seja considerada uma verdadeira esfera pública global. Para tal, vale-se de breve escorço doutrinário sobre o conceito de esfera pública e seus elementos. Posteriormente, confronta tais premissas com a atual estrutura da Web 2.0, revelando alguns riscos para o exercício da cidadania na atualidade.

A hipótese é a de que o papel de local de representação política por excelência, exercido ainda hoje pelo Parlamento em Estados democráticos, parece estar em cheque, fato que cada vez mais traz uma profunda questão de fundo: a sua função atual na estrutura estatal hodierna.

\footnotetext{
* Nesse sentido, a entrevista de Cass Sustein, um dos signatários do relatório direcionado ao governo do Estados Unidos sugerindo reformas na política de vigilância que causou perplexidade em todo o mundo, conhecida por "big data" ou "metadata" [28]. V. também o relatório na íntegra [13].
} 
Muitos autores valem-se da noção de esfera ou espaço público na teoria democrática. Entretanto, a doutrina recorre amiúde à obra de Jürgen Habermas para a compreensão mais aproximada do conceito. In verbis:

Esfera ou espaço público é um fenômeno social elementar, do mesmo modo que ação, o ator, o grupo ou a coletividade; porém, ele não é arrolado entre os conceitos tradicionais elaborados para descrever a ordem social. A esfera pública não pode ser entendida como uma instituição, nem como uma organização, pois, ela não constitui uma estrutura normativa capaz de diferenciar entre competências e papeis, nem regula o modo de pertença a uma organização, etc. Tampouco ela constitui um sistema, pois, mesmo que seja possível delinear seus limites internos, exteriormente ela se caracteriza de horizontes abertos, permeáveis e deslocáveis. A esfera pública pode ser descrita como uma rede adequada para a comunicação de conteúdos, tomadas de posição e opiniões; nela os fluxos comunicacionais são filtrados e sintetizados, a ponto de se condensarem em opiniões enfeixadas em temas específicos. Do mesmo modo que o mundo da vida tomado globalmente, a esfera pública se reproduz através do agir comunicativo, implicando apenas o domínio de uma linguagem natural; ela está em sintonia com a compreensibilidade geral da prática comunicativa cotidiana [20].

Como se pode notar, o conceito mescla elementos negativos e positivos, porém, a análise posterior vai delimitando suas características fundamentais. Dos pontos mais marcantes está a posterior diferenciação entre "atores" e "plateia”, em um ambiente em que alguns grupos ou indivíduos exercem maior influência sobre a opinião de outros [20].

Assim, a luta por influência acaba por revelar os liames da chamada sociedade civil, que mescla o público e o privado no arrebatamento de opiniões favoráveis às pretensões de um ou outro grupo de indivíduos. E, contemporaneamente, segundo o autor, exercem papel decisivo neste ambiente os meios de comunicação de massa, determinantes na formação da chamada opinião pública.

Finalmente, destaca-se ainda que, no arranjo institucional do que Robert A. Dahl denomina de segunda geração da democracia [16], cujas estruturas ainda estão fortemente presentes, a opinião pública exerce grande influência no Estado, direcionando os debates políticos para os períodos de eleição, embora não somente. Portanto, os debates no espaço público que formam a opinião pública tenderiam a se refletir na composição do Parlamento, e em todas as instituições que integram sua formação (formal ou informalmente), como partidos políticos e grupos de interesses.

\section{A INTERNET COMO ESFERA PÚBLICA GLOBAL}

Postas algumas noções acerca do conceito de esfera pública na obra de Habermas, percebe-se que se trata, em linhas gerais, de uma rede de comunicações onde "atores" e "plateia" se misturam como players na busca por influência e, naturalmente, pelo poder 
político. E, desta forma, a eclosão das Tecnologias da Informação e Comunicação naturalmente provocaria também sensíveis alterações estruturais também nesta seara.

Assim, não faltaram e não faltam vozes para identificar na Internet um verdadeiro espaço público por excelência, profícuo para o debate franco e aberto de ideias, onde é possível o exercício pleno das liberdades de expressão, comunicação, informação nas perspectivas ativa e passiva. Nesse sentido, também a importante contribuição de Manuel Castells $[14]^{* *}$.

Outros autores também revelam inegável entusiasmo com o potencial não só da Internet, mas das TICs, para a formação de um ambiente de ciberdemocracia planetária [20]. Ainda que salientem ser, por exemplo, a ausência de privacidade na sociedade contemporânea um enorme risco para a profusão destes ideais democráticos [20], acabam por concluir que a democracia se globalizou, fazendo frente à "globalização do capital”, e se revelará em três grandes frentes: (1) a promoção de experiências democráticas locais; (2) a formação de um governo global; (3) o desenvolvimento de virtudes cívicas que englobam consumo, investimento e trabalho [20 $]^{* * *}$.

Analisando o fenômeno, por seu turno, Siva Vaidhyanathan destaca que "a obra de Habermas influenciou esforços de reforma da mídia e - em uma extensão muito menor - a política midiática. Exaustos por tentar reconstruir a Ágora grega, nós temos que nos concentrar em tentar construir melhores cafeterias" [30], referindo-se à famosa passagem do autor que atribui às cafeterias na Europa o papel de formação da opinião pública na sociedade burguesa.

Entretanto, posteriormente, Siva tece críticas não só ao conceito de esfera pública em si, ao que atribui a pecha de restrito histórica e geograficamente ${ }^{* * * *}$, como à asserção de que a Internet atual pode ser comparada à "sociedade civil cosmopolita ou sua prima, esfera pública global” [30]. Mas a pedra de toque nas observações de Vaidhyanathan diz respeito à atuação de um agente específico na Internet atual e dos riscos ao papel de locus de discussão de questões políticas atribuído a ele: o Google. Para o autor, a aplicação do conceito de relevância nos filtros dos mecanismos de busca, o que influencia na personalização de informações que chegam ao usuário/consumidor final, influi fortemente na sua formação de opinião e, naturalmente, na estruturação de um espaço aberto de discussões políticas voltadas à formação da opinião pública.

Quando um único provedor de aplicações de Internet é responsável por significativo

\footnotetext{
**Em obra posterior, o autor afirma corroborar sua tese ao analisar como as redes sociais contribuíram para a eclosão de uma série de manifestações populares, como a marcha dos indignados na Espanha (2011-2012), a dita primavera árabe em vários países do Oriente Médio (2011-2012) e mesmo os protestos no Brasil que se iniciaram com o movimento Passe Livre, na cidade de São Paulo, mas se alastraram por todo o país durante a Copa das Confederações FIFA. Cf. [13] passim.
}

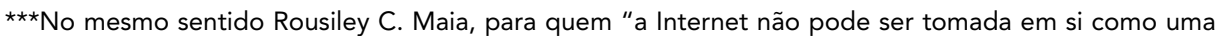
esfera pública". Cf. Democracia e Internet como esfera pública virtual: aproximação das condições da deliberação. [19] Grifos nossos.

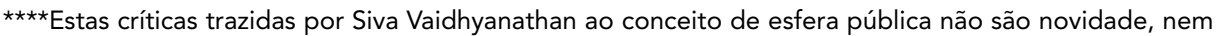
mesmo ao próprio Habermas. Afinal, o conceito de esfera pública apresentado originalmente na década de 1960, foi inteiramente reformulado pelo autor alemão, que incorporou as críticas externas na tentativa torná-lo a-histórico e geral. Cf. [1].
} 
tráfego de informações não é difícil afirmar que exerce grande influência sobre uma Rede que supostamente nasceu para ser descentralizada*****. Não obstante, como diz o próprio autor na abertura de sua obra, o problema não está no Google, mas como, quanto e por que o usamos tanto [30]. Como se sabe, a Internet na atualidade é baseada na estrutura da dita Web 2.o. Trata-se de um slogan [25] para aludir a um conjunto de modelos de negócios dos provedores de aplicação em que o usuário produz o conteúdo e tal informação é o principal capital do empresário, criando um meio mais eficiente para o publicitário por fazer chegar o anúncio direcionado às preferencias do consumidor*****.

No tocante ao exercício da cidadania, Antônio Perez Luño, apoiado em Cass Sustein, afirma que é possível identificar duas perspectivas de cidadania nesse ambiente tecnológico. A primeira, a “cybercidadani@”, revela os inegáveis aspectos positivos do uso da tecnologia para acesso ao conhecimento, à informação, para o incremento da transparência, dentre outros [27].Não obstante, conforme destaca Sustein, a Internet e suas regras baseadas em modelos privados de apropriação acabam por gerar um espaço aparentemente público, mas que no fundo é fruto de um simulacro, uma "republica.com", cujo modelo de cidadania é o da "cidadani@.com”. Em linhas gerais, tratam-se de cidadãos cuja consciência cívica é movida pelo consumo de informação, marcados pela passividade [29]******.

Ao analisar as perspectivas para a democracia na sociedade informacional, Marciele Berger Bernardes distingue duas atitudes antagônicas: otimistas e pessimistas. Dentre os primeiros, os supracitados Castells e Pierre Levy. Dentre os segundos, Lawrence Lessig ${ }^{* * * * * * * *}$, Zygmunt Bauman [2] $]^{* * * * * * *}$. Ainda que pareça superficial adotar o critério "otimista vs. pessimista" para categorizar as densas obras analisadas, Antonio Perez Luño também adota fator de classificação semelhante, ao atribuir a Sustein o rótulo de "pessimista" quanto à democracia na Internet, visão à qual parece se alinhar [29]. Para se debruçar sobre o problema das perspectivas para o Parlamento, e da democracia como um todo, frente às Tecnologias da Informação e Comunicação, não basta a filiação às visões genericamente divididas em "pessimistas" ou "otimistas".

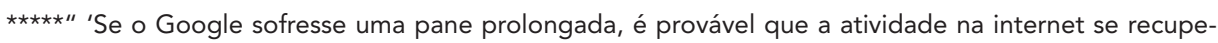
rasse logo, à medida que empresas e usuários mudassem para serviços semelhantes', diz o site Business Insider. 'No entanto, é alarmante o fato de que uma única companhia tem tanta influência sobre uma indústria tão grande e importante.' " [31] Grifamos.

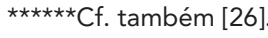

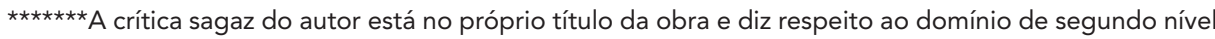
".com", o qual, segundo as regras já consagradas da ICANN sobre nomes de domínio, são reservadas a empreendimentos privados com fins empresariais.

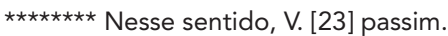

$\star \star \star \star \star \star \star \star A$ autora claramente parece estar entre os "otimistas": "A partir disso, evidencia-se que o Estado, governo e processo de tomada de decisões foram gradualmente transformados pelas mudanças tecnológicas, uma vez que as possibilidades de uso das TICs são múltiplas, podendo inclusive facilitar/ promover mudanças organizacionais a depender do seu uso. Se conservador, implica subutilização de ferramentas e simples transferência para os meios digitais das velhas estruturas; se revolucionário, pode resultar no alvor de uma sociedade mais democrática e participativa
} 
Com efeito, Gustavo Zagrebelsky procura uma via tercis na análise dos postulados democráticos. Trata-se da chamada democracia crítica, situada entre a atitude cética e a dogmática [32].Esta é a atitude perante a questão da possibilidade de a Internet hoje ser considerada uma esfera pública global, capaz de substituir toda e qualquer forma de representação política tradicional e suas estruturas jurídicas em curto espaço de tempo. Sem abandonar a utopia de uma democracia direta, mas atenta aos riscos de tecnologias da qual a humanidade cada vez se torna mais dependente e, ao mesmo tempo, que são desenvolvidas e geridas de acordo com interesses de poucos e poderosos conglomerados empresariais.

\section{PERSPECTIVAS PARA O LEGISLATIVO CONTEMPORÂNEO: É POSSÍVEL SUPERAR O PARLAMENTO COMO ELO CENTRAL DO PROCESSO LEGISLATIVO?}

A conjugação das Tecnologias da Informação e Comunicação com os postulados democráticos, conforme exposto, aumentou consideravelmente as possibilidades para a manifestação da vontade popular. Dessa forma, não faltaram (e não faltam) vozes a proclamar que o ambiente atual revela-se fértil em experiências cuja "eliminação de intermediários" também na seara política estatal. Entretanto, conforme também ressaltado, a reconhecimento das potencialidades não pode ocorrer sem a mensuração dos riscos.

Sabe-se que a substituição de intermediários é uma antiga promessa da Internet. A eclosão de um ambiente tecnológico originalmente descentralizado e tecnologicamente neutro ainda leva muitos a concluírem que esta será a força motriz da democracia participativa no futuro, superando a influência negativa sobre a esfera pública em épocas anteriores exercida pela mass media, como a televisão e a imprensa. Entretanto, para Eli Pariser, apoiado em Tim Wu, trata-se de uma promessa não cumprida, à medida que a Internet não eliminou intermediários, mas apenas os substituiu [26].

A questão é também posta à representação política e, naturalmente, ao seu locus tradicional nas democracias contemporâneas: o Parlamento. Principalmente quando é possível verificar que os moldes tradicionais da representação vão se tornando cada dia mais anacrônicos, levando muitos a concluírem se tratar de uma crise de representatividade política ou, simplesmente, um alto déficit democrático entre a vontade do representante e a vontade do representado.

Antes de enfrentar o complexo problema da necessidade ou não de um Parlamento na atualidade, é necessário averiguar qual a sua função no Estado contemporâneo. As funções do poder legislativo são sintetizadas por Kildare Gonçalves Carvalho [11]:

a) Representativa, traduzida na capacidade única do legislativo em simular o mosaico social, protegendo minorias por dar-lhes poder de voz e voto na produção das normas;

b) Obstrucionista, freando os ímpetos do poder Executivo, unilateral e pessoal, já que se trata de Órgão colegiado. É o que lhe atribui caráter mais conservador; 
c) Mobilizadora do poder popular, promovendo a articulação entre a execução de políticas públicas e a vontade popular;

d) Informativa, divulgando fatos no intuito de diminuir a distância entre cidadãos oe os representantes;

e) Educadora, alcançada por sua maior visibilidade e apelo a questões morais e éticas;

f) Eletiva, típica do parlamentarismo, onde o parlamento escolhe o primeiro ministro.

No Brasil, restringindo-se ao Congresso Nacional, é possível identificar que estão presentes a quase totalidade das funções no sistema constitucional, com ressalva da eletiva. Não obstante, tampouco faltam vozes para verificar a falta de efetividade prática em sua atuação.

Isto porque a dita "crise de representatividade" é algo recorrente entre a doutrina, dela decorrendo, por exemplo, entraves como: as dificuldades de exercício da iniciativa popular; a composição de uma bancada governista a obstar o exercício da função obstrutiva (e todas as outras); a formação de grupos de pressão multipartidários atuando de acordo com seus próprios interesses (bancada ruralista, "evangélica" etc.); a pouca informação prestada pelo próprio legislativo e a maior visibilidade dada ao poder executivo; dentre tantos outros fatores que levam muitos a afirmar que o legislativo hoje está mais próximo de um problema do que uma solução para o "gap de representatividade".

Portanto, muitos questionam se a solução para o problema seria o fim do Parlamento. Robert A. Dahl, por exemplo, afirma que não. No que denomina de "Poliarquia III”, em superação às poliarquias da primeira e segunda geração da democracia [16], o autor enumera algumas possibilidades com ressalvas[16]. Afirma o autor que um determinado país poderia até criar uma espécie de "conselho permanente", um pequeno grupo de cidadãos eleitos para auxiliar a tomada de decisões políticas, o que chama de um minipopulus. 'Os membros de um minipopulus poderiam 'se reunir' por meio das telecomunicações," afirma [16]. Por outro lado, outros afirmam que sua atuação no processo legislativo vai torná-lo cada vez mais interativo. Esta é a visão de Cristiano Ferri Soares de Farias, um dos idealizadores do projeto e-democracia da Câmara dos Deputados. Para ele, há dois tipos de experiências em e-democracia, as institucionais e as não institucionais. Analisando experiências interativas promovidas no âmbito do Poder Legislativo, conclui o autor que da simbiose entre os princípios clássicos da democracia representativa e os da democracia participativa, surge a interatividade digital no parlamento [18]. Por último, é também possível asseverar que o Parlamento preservará e fortalecerá seu poder de fiscalização de outros poderes, mormente o Executivo. Não obstante, que seu papel de elo central no processo legislativo será paulatinamente substituído por outros mecanismos, ganhando força os não institucionais de participação e manifestação da vontade popular. E nesse aspecto, a Internet ganha grande relevância. 
As Tecnologias da Informação e Comunicação introduziram alterações sociais profundas e significativas. Ao passo que seu uso se alastra, parece que cada vez mais se está diante de um caminho sem volta, cujas consequências devem ser mensuradas, porém não podem ser evitadas.

Este trabalho procurou averiguar um aspecto problemático, qual seja a capacidade de o ambiente político propiciado pela maciça utilização das TICs, principalmente a Internet, vir a ser considerado um espaço público ou esfera pública em âmbito global.

Primeiramente, procurou-se trabalhar alguns aspectos estruturantes do conceito de esfera pública, sua importância para a teoria democrática e as críticas às suas premissas. Posteriormente, foi trabalhada a problemática acerca da viabilidade de a Internet vir a ser considerada como uma ferramenta de promoção e desenvolvimento de uma esfera pública em âmbito global.

Ao final desta primeira etapa, concluiu-se que a Internet, hoje, não é a mesma de quando surgiu. Portanto, para que seja uma ferramenta de efetiva promoção dos postulados democráticos e naturalmente de consecução de uma esfera pública em âmbito global é necessário que se tome uma postura crítica, que supera a visão cética, mas tampouco tem atitude otimista cega.

Assim, é necessário estar atento às peculiaridades da Web 2.0, cuja atuação de filtros de conteúdo indica para um ambiente de informações "personalizadas" segundo as supostas preferências do usuário, desenvolvido segundo interesses de promoção de produtos e serviços e cujas consequências para a democracia podem ser significantemente negativas.

Logo, após descrever tal ambiente, foi possível enfrentar algumas perspectivas para a representação política e especialmente para o legislativo, materializado na figura do parlamento. Atendo-se ao processo legislativo, afirmou-se que não é unânime a asseveração de que a tecnologia certamente levará à consolidação da democracia direta. Ao menos em curto prazo.

Isto porque há aqueles que afirmam que, mesmo com a possibilidade de manifestação direta da vontade política pela população, não será possível se prescindir da representação, que poderá se valer das tecnologias, mas nunca desaparecerá.

Por sua vez, há quem identifique já um movimento crescente de utilização destas tecnologias pelo próprio poder legislativo, para fins de promoção de um ambiente que faz do Parlamento um ambiente cada vez mais interativo e do processo legislativo algo colaborativo.

Por último, é possível identificar quem assevere que tal ambiente levará a uma paulatina perda de função do poder legislativo como protagonista do processo legislativo, restando-lhe o exercício de outras funções atípicas, o que poderá ser fortalecido pela maciça utilização das TICs.

Não há resposta pronta, mas é certo que o problema está lançado e a única certeza que resta é a de que é necessário o aprofundamento do estudo acerca das potencialidades da Internet, bem como dos desafios para sua promoção e desenvolvimento, o que passa pela imposição de limites efetivos a interesses que podem ferir de morte 
as esperanças de um futuro mais democrático.

\section{REFERÊNCIAS}

[1] BARROS, A. P. F. L.. A importância do conceito de esfera pública de Habermas para a análise da imprensa - uma revisão do tema. In: Universitas: Arquit. e Comunicação Social, Brasília, v. 5, n. 1/2, p. 23-34, jan./dez. 2008.

[2] BAUMAN, Z. Danos colaterais: desigualdades sociais numa era global. Trad. Carlos Alberto Medeiros. Rio de Janeiro: Zahar, 2013.

[3] BEÇAK, R.; LONGHI, J. V. R.. Tendências da democracia participativa: a influência da Internet no perfil da representação e evento do orçamento participativo. In: XX CONGRESSO NACIONAL do CONPEDI, Vitória-ES. A Ordem Jurídica Justa: um diálogo Euro-Americano, 2011.

[4] _. ____. Democracia deliberativa e ciberdemocracia: riscos e desafios para sua implementação. In: Anais do XXIII CONGRESSO NACIONAL DO CONPEDI, Conselho Nacional de Pesquisa e Pós-graduação em Direito. São Paulo, 13-16. nov. 2013.

[5] _ . _ _ A democracia participativa e sua prospecção futura - perspectiva histórica e prospecção futura: o marco civil para a regulação da Internet no Brasil. In: SIMÃO FILHO, A. et alli (coord.). Direito da Sociedade da informação: temas jurídicos relevantes. São Paulo: Quartier Latin, 2012. ; . Processo Legislativo Colaborativo: a participatividade pela internet no trâmite do Projeto de Lei n. 2.126/2011 (Marco Civil da Internet). Anais do XXI Congresso Nacional do CONPEDI, Niterói-RJ, 31 de out.-3 de nov. de 2012, em.

[7] BEÇAK, R. A hipertrofia do executivo brasileiro: o impacto da constituição de 1988. Campinas: Millennium, 2008.

[8] . Estado de direito, formas de Estado e constituição. In: Revista da Faculdade de Direito de Conselheiro Lafaiete. nova fase. v. 3, 2007a. p. 293295. Versão deste artigo apareceu, alguns anos depois, com o mesmo título, na Revista Em tempo. Revista da área de Direito do UNIVEM. v. 10, 2011.

[9] _ Reflexões sobre o evolver democrático rumo à sua otimização: a atualidade da "democracia deliberativa" e suporte teórico. Enfoque histórico-evolutivo. Contribuição à Teoria Geral do Estado. 2012. 178f. Tese (Livre-docência em Teoria do Estado). Faculdade de Direito, USP, São Paulo, 2012.

[10] BERNARDES, M. B. Democracia na Sociedade Informacional: o desenvolvimento da democracia digital nos municípios brasileiros. São Paulo: Saraiva, 2013.

[11] CARVALHO, K. G. Direito constitucional: teoria do estado e da constituição; direito constitucional positivo. 15 ed. rev., atual. e ampl. Belo Horizonte: Del Rey, 2009.

[12] CASTARDO, H. F. Natureza jurídica do Tribunal de Contas no 
Ordenamento Brasileiro. 2007. 19of. Dissertação (Mestrado em Direito) Faculdade de Direito, UNIMEP, Piracicaba. 2007. Disponível em: <https:// www.unimep.br/phpg/bibdig/pdfs/2006/YTAVWAIQBHIT.pdf $>$. Acesso em: 1 fev. 2014.

[13] CASTELLS, M. Redes de indignação e esperança. Rio de Janeiro: Zahar, 2013.

[14] The New Public Sphere: Global Civil Society, Communication Networks, and Global Governance. In: Annals of American Academy, n. 616, March, 2008. Disponível em: <http://annenberg.usc.edu/Faculty/Communication\%2oand\%20Journalism/ /media/78.ashx>. Acesso em: 27 jan. 2014.

[15] CLARKE, R. A.; MORELL, M. J.; STONE, G. R.; SUSTEIN, C. R.; SWIRE, P. Liberty and security in a changing world: Report and Recommendations of Report and Recommendations of The President's Review Group on Intelligence and Communications Technologies. Disponível em: <http:// s3.documentcloud.org/documents/929267/review-group-exec-summary-and-recs.pdf $>$. Acesso em: 26 jan. 2014.

[16] DAHL, R. A. A democracia e seus críticos. Trad. Patrícia de Freitas Ribeiro; rev. de trad. Aníbal Mari. São Paulo: WMF Martins Fontes, 2012.

[17] ESTADÃO. Facebook tira do ar página de divulgação de protestos contra a Copa: Página com mais de 16 mil curtidas foi deletada na terça-feira; movimentos falam em censura. Disponível em: <http://www.estadao.com. $\mathrm{br} /$ noticias/cidades,facebook-tira-do-ar-pagina-de-divulgacao-de-protestos-contra-a-copa,1124387,o.htm>. Acesso em: 30 jan. 2014.

[18] FARIA, C. F. S. de. O parlamento aberto na era da internet: pode o povo colaborar com o Legislativo na elaboração das leis? Brasília: Câmara dos deputados, edições Câmara, 2012. p. 293. Disponível em: <http://bd.camara. gov.br/bd/bitstream/handle/bdcamara/7867/parlamento_aberto_faria. pdf? sequence $=2>$. Acesso em: 1 fev. 2014.

[19] GOMES, W.; MAIA, R. C. M. Comunicação e democracia. Problemas \& perspectivas. São Paulo: Paulus, 2008.

[20] HABERMAS, J. Direito e democracia: entre faticidade e validade. Vol. II. Trad. Fabio Beno Siebneichler. Rio de Janeiro: Tempo Brasileiro, 1997.

[21] HINDMAN, M. The myth of digital democracy. Princeton: Princeton University Press, 2009.

[22] LEMOS, A.; LEVY, P. O futuro da Internet: em direção a uma ciberdemocracia planetária. São Paulo: Paulus, 2010.

[23] LESSIG, L. Code and other laws of cyberspace. New York: Basic Books, 1999.

[24] LONGHI, J. V. R.. Privacidad, democracia y redes sociales en Brasil: ¿ Primavera o inverno? In: Medialaws. Disponível em: <http://www.medialaws.eu/privacidad-democracia-y-redes-sociales-en-brasil-primavera-o-inverno/>. Acesso em: 27 jan. 2014.

[25] O'REILLY, T. What Is Web 2.0: Design Patterns and Business Models for the Next Generation of Software. Disponível em: <http://oreilly.com/web2/ archive/what-is-web-20.html>. Acesso em: 08 fev. 2014. 
[26] PARISER, E. O filtro invisível. O que a Internet está escondendo de você. Trad. Diego Alfaro. Rio de Janeiro: Zahar, 2012.

[27] PÉREZ LUÑO, A. E. Internet y Derechos Humanos. Derecho y conocimiento: anuario jurídico sobre la sociedad de la información y del conocimiento. Universidad de Huelva (Facultad de Derecho), Huelva, n. 2, p. 101-121, 2002.

[28] ROSEN, J. The New Republic - "Metadata Material Shouldn't be Held by the Government. Interview: A key NSA reform panelist explains their recommendations. Disponível em: <http://www.newrepublic.com/article/116027/ nsa-reform-report-panelist-cass-sunstein-metadata-storage $>$. Acesso em: 26 jan. 2014

[29] TREIN, A. Ciberdadani@ e República.com: reflexões a partir de Cass Sunstein e Perez Luño. Revista Democracia Digital e Governo Eletrônico, n. 9, p. 1-23, 2013. Disponível em: <http://buscalegis.ufsc.br/revistas/index.php/ observatoriodoegov/article/view/34274>. Acesso em: 31 jan. 2014.

[30] VAIDHYANATHAN, S. Googlization of Everything (and why should we worry). Berkeley/Los Angeles: University of California Press, 2012.

[31] VEJA. Google tem pane de 5 minutos e o tráfego na internet cai 40\%. Disponível em: <http://veja.abril.com.br/noticia/vida-digital/falha-no-google-causou-queda-de-40-no-trafego-da-internet-no-mundo>. Acesso em 28 jan. 2014.

[32] ZAGREBELSKY, G. A crucificação e a democracia. São Paulo: Saraiva, 2011.

RUBENS BEÇAK professor associado da Faculdade de Direito de Ribeirão Preto (graduação e pós-graduação) e da Faculdade de Direito (pós-graduação) da Universidade de São Paulo. Secretário Geral da Universidade de São Paulo (2010-14) - e-mail: prof.becak@usp.br

JOÃO VICTOR ROZATTI LONGHI professor assistente da Faculdade de Direito da Universidade Federalde Uberlândia-e-mail: joaovrlonghi@yahoo.com.br 